\title{
TENSÕES NO ESPAÇO PÚBLICO DE CIDADES EUROPEIAS: PROCESSOS DE DESPOLITIZAÇÃO E RESTRIÇÕES DA CIDADANIA CULTURAL
}

\author{
Francisco Antônio Zorzo ${ }^{1}$
}

\begin{abstract}
Resumo: Trata-se de uma investigação sobre o uso atual do espaço público em cidades europeias com o objetivo de entender e descrever como esse espaço se modifica com os acontecimentos políticos. Escolheram-se duas cidades, Roma e Barcelona para investigar e, durante o período de julho e outubro de 2016, através de entrevistas com ativistas e pesquisadores sobre a questão da cidadania cultural, bem como através do acompanhamento de manifestações e atos políticos, chegou-se aos seguintes resultados: a) o espaço público está cada vez mais privatizado; b) há forte investimento do próprio estado, sob interesse do capital, na despolitização dos atos e movimentos. Em suma, sem uma nova pedagogia derivada desses conflitos e contra investimentos neoliberais no esvaziamento da vida pública, o cenário mostra-se complicado para a construção de movimentos mais efetivos de ocupação dos espaços das cidades. $\mathrm{O}$ artigo traz reflexões para o desafio de promover a participação popular voltada à democracia e à transformação social e, com isso, ampliar a vivência e a conquista da cidadania cultural.
\end{abstract}

Palavras-chave: Cidadania cultural. Espaço público. Privatização.

\section{TENSIONS IN THE PUBLIC SPACE OF EUROPEAN CITIES: DISPOLITIZATION PROCESSES AND RESTRICTIONS OF CULTURAL CITIZENSHIP}

\begin{abstract}
This is an investigation on the current use of public space in european cities in order to understand and describe how this space changes with political events. Two cities were chosen to investigate, Rome and Barcelona, during the period from July to October 2016. Through interviews with activists and researchers on the subject of cultural citizenship, and over the observation of political acts, the following results were obtained: a) public space is increasingly privatized; b) there is a strong investment by the state in accordance with the interests of capital, and depoliticization of acts and movements. In short, without a new pedagogy derived from these conflicts, and against these neoliberal investments in the emptying of public life, the scenario seems to be complicated to build more effective movements and occupation of spaces in the cities. The paper brings reflections on the challenge of promoting popular participation focused on democracy and social change and, thereby, increase the experience and the conquest of cultural citizenship.
\end{abstract}

Keywords: Cultural citizenship. Public space. Privatization.

\footnotetext{
${ }^{1}$ Professor Adjunto do BI em Humanidades da UFBA. E-mail: fazfeira@gmail.com.
} 


\section{Introdução}

Quais os fatores que atingem a cidade contemporânea e que afetam o espaço público e de convivência? Essa pergunta está no núcleo de uma pesquisa recente, de pós-doutorado, realizada de março de 2016 a fevereiro de 2017, sobre o espaço público na cidade europeia contemporânea. Ela foi formulada para um grupo focal de entrevistados ao longo do período de estágio pós-doutoral em Roma (UR3/Architettura, sob supervisão do professor Francesco Careri). As respostas à pergunta indicaram o modo como o espaço público está sendo construído nas metrópoles globais, como Roma e Barcelona.

O momento político europeu se mostra bastante complicado. Principalmente porque há pouco debate (debate político efetivo para a mudança) e se impõe uma lógica preponderantemente conservadora. A "ricerca" ocorreu em meio a uma fase de crise democrática, em que as transformações urbanas do capitalismo em curso, tendem a afastar os cidadãos da participação política.

Devemos precisar o que entendemos como espaço público. Evidentemente, o espaço público é uma construção social polifônica, que requer mais do que solo urbano e que o desenho de uma praça, vindo a se tornar o lugar de debate e pensamento politico, com um empenho coletivo para que as pessoas o frequentem como ágora (no sentido da democracia grega). Espaço público aqui tem o sentido de lugar de debate, de crítica, de enfrentamento dos problemas de uma cidade, com o posicionamento explícito dos cidadãos. No espaço público se dão os acontecimentos e as performances que ativam o seu potencial transformador (MARZADRO; ZORZO, 2013). Como conceito polifônico, Espaço público quer dizer que os cidadãos nem sempre tem o mesmo conceito para esse lugar em questão, nem os cientistas sociais e nem mesmo os políticos.

O principal argumento da pesquisa é que hoje temos o espaço público sob uma forte tensão. Esse tensionamento do espaço comum decorre do esvaziamento do seu caráter político. E, por outro lado, vem sendo atacado o seu papel como potencial lugar de encontro das diferenças, devido a uma pressão decorrente dos processos de privatização e homogenização de funções. 
TENSŌEES NO ESPAÇO PÚBLICO DE CIDADES EUROPEIAS: PROCESSOS DE DESPOLITIZAÇĀO E RESTRIÇÔ̄ES DA CIDADANIA CULTURAL

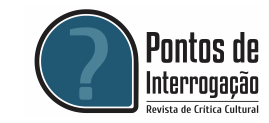

Quais são as transformações no espaço privado e como elas afetam o espaço público? Ora, temos o espaço urbano como resultado de processos de territorialização que devem ser estudados. Em primeiro lugar, o espaço urbano cresce muito desde o final do século XIX. A partir dos problemas advindos dessa expansão do espaço sobre terrenos privados, forma-se, em certa porção, o espaço público. Essa porção é minoritária. Temos, então o espaço público que é uma construção delicada e muito ameaçada pelas diversas formas de privatização. O espaço público varia com a politica e no momento atual, pode-se dizer, passa por uma retração. E, um outro mecanismo de desterritorialização se pronuncia, a esfera comunicacional que alimenta o espaço urbano de signos, noticias e propaga os eventos, que cresce ainda mais rapidamente que o primeiro nas últimas decadas.

A esfera comunicacional tem um efeito concectivo importante. Isso é inegável. Ela também poderia ser politizada, mas em geral, na lógica do capitalismo atual, está sendo conduzida (pode-se pensar em grandes coorporações da informação e da computação) de modo a evitar os verdadeiros conflitos. No apelo crescente ao consumo, a esfera comunicativa evita a critica ao status quo. Enfim, a esfera comunicacional pública funciona de modo conservador, reconcentrando o poder. Repetição do mesmo e maior grau de visibilidade ou marketing é a tendência dominante.

Frente à esfera comunicacional, o espaço urbano é pressionado em seu papel de "contenitore" nos termos do estudo de Bruzzese (2013). O sistema cultural e comunicacional dominante, que despeja no espaço urbano uma enorme quantidade de propaganda e todo tipo de informação, bascula usos privados tanto no ambiente doméstico como nos lugares ditos públicos. Foi comum ver no período da pesquisa, em atos nas praças romanas, usuários mais conectados com o celular do que com as manifestações em curso contra uma medida do governo.

Em fase atual de crise democrática, o espaço público é uma construção da sociedade que requer educação e participação cidadã crítica. Deveria ser o lugar mais performático e concreto do exercício do poder. Ele deveria contemplar as diferenças, os movimentos da população e, portanto, o enfrentamento explícito de lutas pela justiça social. Como se diz na Itália, "Muro polito, città muta (parede limpa, povo calado). Há aqui uma noção viva de crítica, de descontentamento, que expresso na pichação, como vontade de exprimir as diferenças.

Pontos de Interrogaçầo, v. 7, n. 2, jul.-dez., p. 47-56, 2017. 


\section{Polêmicas em torno de processos de privatização e restrições de uso do espaço público em cidades europeias}

Durante o pós-doutorado foram acompanhados diversos eventos e manifestações que ajudam a entrever as dinâmicas e os conflitos que afligem o espaço público nas metrópoles contemporâneas. Dois exemplos podem ser pinçados, para se analisar alguns dos principais problemas ligados ao uso da praça e ao debate crítico-cultural, um ocorrido no centro de Roma, no largo em frente à igreja da Madona dei Monti e um no centro de Barcelona, na entrada do Mercado do Born.

O exemplo de conflito no centro de Roma foi a reação de um gerente de um restaurante-escola devido a proibição e multa por uso do espaço frontal ao estabelecimento. Ele recebera uma multa alta, da ordem de milhares de euros, por uso do espaço situado no largo da igreja, dispondo algumas mesas e cadeiras para consumidores. O gerente fez um protesto acorrentando-se diante do restaurante e chamando a atenção do público e das mídias sociais para o problema (ver figura 1, que ilustra o ocorrido).

O gerente fez o protesto pra chamar a atenção do poder público e da comunidade, pois o restaurante era conveniado com o poder público (Il Comune), por se tratar de um restaurante-escola para "albergues" (hotelaria). Como tal, o restaurante tinha a atribuição de proporcionar experiências de ensino nas atividades de formação dos jovens aprendizes dos serviços de restaurante e hotelaria. O protesto continuou com uma ação cultural, na semana seguinte, em que muitos artistas, os políticos e a comunidade foram convidados a participar no largo da igreja. O evento contou com o apoio da prefeitura (através da presença do vice-sindacona época, Daniele Frongia).

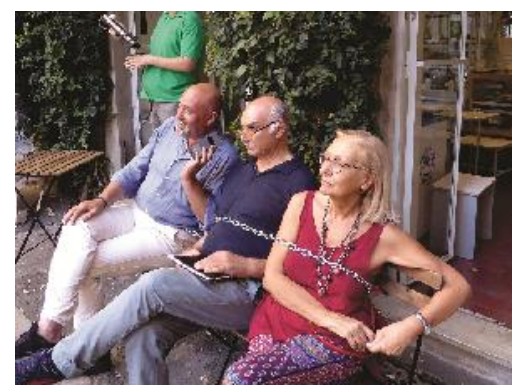

Fig.1: Foto de protesto de gerente de restaurante a respeito da proibição do uso do espaço na frente de estabelecimento em Roma (Foto: Francisco A. Zorzo, Julho de 2016) 
TENSŌES NO ESPAÇO PÚBLICO DE CIDADES EUROPEIAS: PROCESSOS DE DESPOLITIZAÇĀO E RESTRIÇÔ̄ES DA CIDADANIA CULTURAL

O exemplo de Barcelona é propicio para uma abordagem do problema da despolitização do espaço público e da debilidade do debate cultural na Espanha contemporânea. Em outubro de 2016, foi exibida uma exposição sobre monumentos franquistas, que haviam sido retirados das vias públicas da cidade. Foi uma tentativa de politizar e discutir a história espanhola recente, mas o desfecho veio repercutir no sentido contrário.

A exposição "Franco, Victoria, República", inaugurada numa segunda-feira, 17 de outubro de 2016 era um projeto historiográfico que debatia a trajetória de monumentos franquistas em Barcelona, tendo como ícones colocados na frente do Mercado do Born, no centro da cidade. Em especial, chamava a atenção do público a estátua a cavalo do general, em que o caudilho estava sem cabeça. A exposição instalada dentro do Mercado do Born foi admitida, mas a estátua foi vandalizada diversas vezes e derrubada, sendo retirada do local pela prefeitura (ayuntamento) em poucos dias.

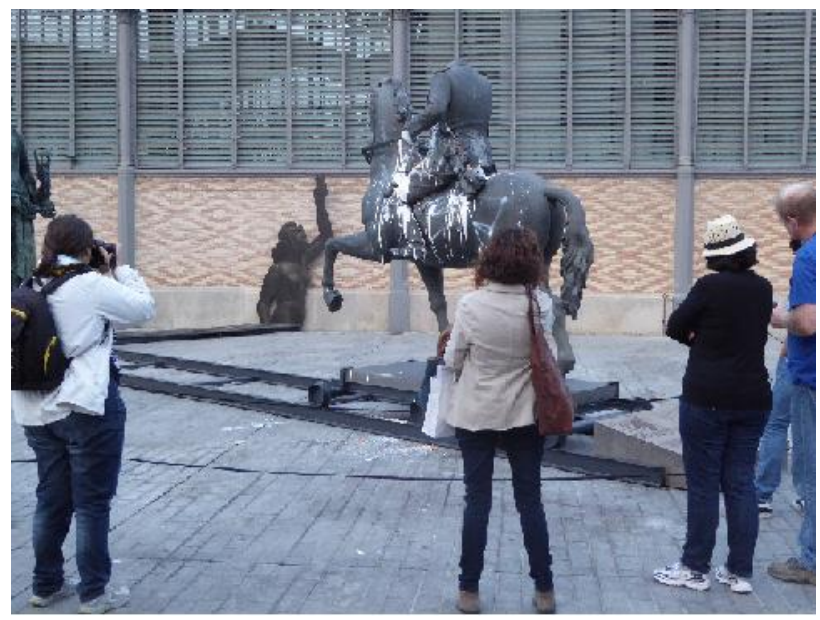

Fig.2 - Foto da polêmica exibição da estátua equeste do Gen. Franco em Barcelona (Foto - Francisco A. Zorzo, outubro de 2016)

Esse fato permite pensar uma contribuição importante sobre a construção do espaço público, tirada do caso barcelonês. O pensador contemporáneo da cidade, Manuel Delgado (2012, p. 23-32), nos avisa para tomarmos cuidado com o fetichismo do espaço público. A tendência ao fetiche e à espetacularização visa um uso despolitizado da praça pública. Ou seja, do ponto de vista libertário, devemos cuidar para não delegarmos peso a 
certas concepções idealizadoras da rua e da praça, evitando um conceito equivocado de espaço público contemporâneo.

O caso da derrubada da estatua do gen. Franco no mercado do Born, explicita como o uso de estátuas e monumentos é conveniente ao sistema cultural dominante, desde que vise algo que se embeleza e se torna um atrativo turístico. Em Barcelona, nas ultimas décadas, tendo em vista o marketing da cidade, se colocou muita arquitetura e arte renomadas no espaço urbano, como verdadeiras vedetes da cidade. Criou-se um fetiche muito convincente e útil. Mas, quando se coloca, numa exposição historiográfica, provocativas estátuas do imaginário político, em local simbólico central, a crise do modelo se intensifica e o objeto cultural entra em colapso. Por razões equivocadas, visando o mal entendido, tanto direita quanto esquerda estavam contra a exposição da estátua. Assim, o debate cultural durou pouco e a prefeitura local, "envergonhada", retirou da cena a fonte da crise.

Os dois exemplos ocorridos no espaço público, um deles em Roma, no largo em frente à igreja da Madona dei Monti e o outro no centro de Barcelona, no Mercado do Born, desencadearam uma sacudida na opinião pública. O primeiro mais inesperado e restrito à vida cotidiana e comercial da metrópole turística e o outro de caráter planejado com vistas ao confronto de ideias na capital catalã, ambas situações permitem um questionamento da representação, colocam o poder público em questão e evocam o posicionamento da população de maneira incomum. Foi uma pena que a discussão ficasse truncada e que os eventos tenham alcance momentâneo, mesmo dentro das suas respectivas comunidades.

Se falta um debate e uma troca de ideias sobre a cidade e o bem comum nos logradouros comuns, sobram consumidores ("costumers", como se diz em inglês, na literatura corrente sobre o tema). Deve-se ter isso em conta, quando se vê que a presença de usuários não garante a vigência do espaço público, a despeito de um imaginário consolidado "della centralità" (BRUZZESE, 2013). Para que o espaço urbano se torne um espaço público é preciso incentivar atividades, acolher a vitalidade dos usos contemporâneos e ir além das meras funções de troca, transporte, consumo e entretenimento. Em Roma, qualquer espaço dito público de ação cidadã, em frente a um palácio de governo, costuma ser frequentado por turistas que, como se sabe, nada tem a ver com os problemas da sociedade civil organizada local, o que 
TENSŌES NO ESPAÇO PÚBLICO DE CIDADES EUROPEIAS: PROCESSOS DE DESPOLITIZAÇĀO E RESTRIÇÔ̄ES DA CIDADANIA CULTURAL

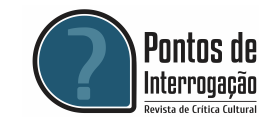

dispersa a atenção do debate político para o campo do consumo do marketing urbano.

$\mathrm{Na}$ atualidade, pensar o espaço urbano em sua dimensão pública conduz a uma relativização, pois não se pode separar totalmente do uso privado. O sentido público do espaço entra em contradição com o espírito da época, tendendo a ser visto como algo concedido. Sob a égide da privatização, tem-se um "sfruttamento" de usos, ou seja, abuso ou pelo menos uma confusão de usos. A tensão decorre do fato de que o que se concede (seria o Estado e seus fantasmas o que concede? Restando a dúvida: até aonde vai o poder público?) é sempre controlado e regulamentado. O que é concedido (o uso público) torna-se parcial, "sotto certi aspetti", como Bauman discute no seu texto "La Libertà" (2002, p. 54). O contorno dos conflitos do uso público ou privado do espaço urbano depende da "isenção de obrigações" e da definição de "jurisdição" em jogo. Portanto, não temos nunca, hoje em dia, espaço 100\% público. O exercício público do espaço depende de pertencimento a uma coletividade maior, de uma instância que que constitui o seu uso comum e regula os privilégios.

Isso leva a refletir, através das entrevistas realizadas na pesquisa, que o problema da redução do espaço público nas ultimas duas décadas, pelo menos em Roma e Barcelona (e também em Salvador, onde estamos presenciando o processo político) decorre dos muitos, heterogêneos e crescentes, processos de privatização. Tal colocação endereça a nossa discussão ao ponto candente de encontrar uma verdadeira distinção entre o político e o econômico dentro da cidade ameaçada pelos processos de privatização. Agrega-se a isso, no caso europeu, que os governos se postam em situação de exceção (militarização anti-terrorismo e vigilância permanente).

$\mathrm{Na}$ forma social tradicional, o espaço urbano (patrimônio imobiliário) era uma base para conceber as relações de poder, que era claramente distinto do capital (patrimônio mobiliário). Na modernidade líquida, isso foi mudado, o ligame entre espaço e política se dividiu e o capital ganha autonomia cada vez maior e com maior dominância. A cidade livre do antigo poder fora, a um tempo, uma conquista das classes emergentes, permitindo a circulação da mercadoria e do capital. Mas isso trouxe por sua vez novas formas de dominação e de problemas para os piores situados socialmente. Esse processo de liquidez se amplia cada vez mais na atualidade.

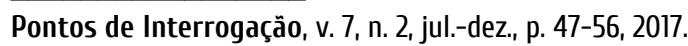


A desigualdade se amplificou na contemporaneidade, já que um outro sistema se estabeleceu e foi se reformulando em ajustes, crises e retomadas. Essa breve revisão, permite pensar o avanço do capitalismo e seus efeitos sobre o espaço público. Com tal avanço a individualidade mudou também, entrando em ressonância com as transformações da economia. A individualidade fortemente ligada ao poder de consumo na era contemporânea parece fazer frente (e somente na aparência reduzindo) a dependência social .

A crise de representação do político vai no sentido da dispersão devida ao poder do dinheiro, ou seja, em vez de autoridade pública voltada a um sentido cívico, um exercício difuso e fluido de poder, a partir do primado do capital. Pode-se definir a nossa forma social geral como uma sociedade despolitizada, conforme Bauman, embalada pelos fluxos do capital.

O espaço publico como lugar de conflito e debate, não existe sem o exercício de liberdade, de um lado, e de normas e regras, de outro. Em sua dinâmica, está sempre sendo produzido e reproduzido sob uma forma política e de acordo com uma autoridade pública legítima (eleita de maneira democrática). A essa autoridade se recorre sempre que o conflito não se resolve durante o confronto imediato dos cidadãos. O espaço público é uma construção social, que é mantida sob exercício político do cidadão, delegado a uma câmara ou "comune".

Esse edifício político, que tem uma fragilidade inerente, pode ser arruinado ou simplesmente desvirtuado se ocorrem infiltrações, perdas e descuidos, como nas nossas democracias esvaziadas ou, até mesmo, ser devastado e petrificado nos regimes autoritários. O maior escândalo por que passou a cidade de Roma nos últimos anos foi chamado de "Roma Capitale", devido ao desvio de recursos das políticas sociais. O sindaco eleito, Ignazio Marino, foi deposto (com renúncia em outubro de 2015) e em seu lugar foi colocado um comissário, de nome Tronca, considerado autoritário pelos movimentos sociais da cidade.

\section{Considerações finais}

Concluindo a partir da ideia de liberdade em Bauman (2002), o espaço público é uma construção frágil. Ele se mantém sob o risco de ser 
TENSŌES NO ESPAÇO PÚBLICO DE CIDADES EUROPEIAS: PROCESSOS DE DESPOLITIZAÇĀO E RESTRIÇÔ̄ES DA CIDADANIA CULTURAL

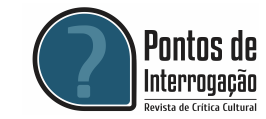

"colocado a serviço" de idealizações e interesses, com aplicação de grandes limitações. As limitações, bem presentes hoje, vão no sentido de tratar o mundo e as pessoas como coisa, de se manobrar e se relacionar com o cidadão através da imagem. Na esfera politico-comunicacional, o coletivo tende a se fazer corresponder a uma imagem, de se utilizar a relação com o outro como um meio para se alcançar um fim. Ou seja, a liberdade admitida e operante no capitalismo, diz Bauman (2002), faz com que as outras pessoas sejam tratadas como objeto e reduzidas a funções, a serem vistas como usuários, operários ou consumidores (se tornando mais objeto que sujeito da ação).

Uma exemplar ocorrência em Roma, como acima indicado, pode ser vista como uma disputa para ampliar o lugar público ou ser sinalizada como um exercício de atividades privadas. Muitos eventos, realizados na praça pública das nossas metrópoles, se baseiam numa ideia de gerar um mercado de consumo e entretenimento, com vendedores e consumidores. O caso em questão se mostrou uma excelente oportunidade de gerar debate e troca de ideias, com palestras e discussão. No entanto, Bauman é claro ao dizer nos estudos da liberdade na sociedade capitalista, ocidental e contemporânea, que o que predomina é a "liberdade de consumo" (BAUMAN, 2002, p. 17-150). Isso não deveria impedir, necessariamente, o debate e a crítica, mas causa uma verdadeira devastação do sentido político do lugar do encontro.

$\mathrm{Na}$ babel contemporânea, temos uma população de "solitari interconnessi”, de solidão contectada por celular, como dizem Bauman e Mauro (2017), ligados pelo fio repetitivo do consumo. As transformações do sistema social depõem contra o espaço público, desmaterializado (“smaterializzato"), por um agressivo bombardeamento vindo da esfera comunicacional (sob diversos tipos de serviço, ditos aplicativos, que contam com a adesão massiva dos cidadãos). Ocorre uma perda de espaço político, pois o acontece que hoje retira o compromisso com o debate e subtrai o cuidado com a memória das lutas. O caso da polêmica retirada da estátua do general Franco, no Mercado do Born em Barcelona, mostra que, tendencionalmente, perde-se o senso de compromisso com a crítica e esvaziase o espaço público. 


\section{Referências}

BRUZESSE, Antonella, Centralità a tempo. Industria creativa, trasformazioni urbane e spazio pubblico a Milano. XVI_Conferenza SIU. Planum_n.27_ vol.II(2013)_Atelier_9a_Full_Papers_I_Rigenerazione_Creativa.pdf

BAUMAN, Zygmunt. La Libertà, Troina: Città Aperta. Ed.., 2002.

BAUMAN, Zygmunt e MAURO, Ezio. Babel. Roma: Laterza/La Repubblica, 2017.

DELGADO, Manuel. Ciudadanismo. Barcelona: Catarata, 2012.

MARZADRO, Flávio e ZORZO, Francisco. Relato de ato coletivo: Post Factum - Ladeira da Montanha. In: Pontos de Interrogação. V. 3. N. 1. Alagoinhas, Jan./jul. 2013.

Recebido em: 08/11/2017

Aprovado em: 12/12/2017 